\title{
O DESAFIO DA INTEGRAÇÃO DE POLÍTICAS PÚBLICAS PARA A ADAPTAÇÃO ÀS MUDANÇAS CLIMÁTICAS NO SEMIÁRIDO BRASILEIRO
}

\author{
MILHORANCE, Carolina - cmilhorance@gmail.com \\ Universidade de Brasília / UNB \\ MENDES, Priscylla - priscylladayse@hotmail.com \\ Universidade de Brasília / UNB \\ MESQUITA, Patrícia - patriciasmesquita@gmail.com \\ Universidade de Brasília / UNB \\ MORIMURA, Michelle - micamidori@gmail.com \\ Universidade de Brasília / UNB \\ REIS, Rafael - rafael.moraesreis@gmail.com \\ Universidade de Brasília / UNB
}

RODRIGUES FILHO, Saulo - saulofilhocds@gmail.com

Universidade de Brasília / UNB

BURSZTYN, Marcel - marcel.cds@gmail.com

Universidade de Brasília / UNB

\begin{abstract}
RESUMO: O artigo discute os desafios das políticas públicas em promover a governança dos recursos naturais na região do Submédio rio São Francisco, em particular as interações por vezes conflituosas entre segurança hídrica, alimentar, energética, e socioambiental. A evolução dos processos de ocupação do território e de implementação de políticas públicas será apresentada numa primeira seção, com foco nos projetos energéticos e suas interações com a utilização de recursos hídricos e com questões produtivas e agrárias. A segunda seção apresenta os dados primários de investimento público na região, cujo alvo tem sido os projetos eólicos, e as interações interinstitucionais para a execução destes recursos. A terceira seção discute os riscos apresentados pelos projetos eólicos, no sentido de reproduzir os padrões desiguais de investimentos no território e aumentar a vulnerabilidade socioambiental, apesar do potencial destes projetos em promover a mitigação das mudanças climáticas.
\end{abstract}

PALAVRAS-CHAVE: Abordagem Nexus; Adaptação às Mudanças Climáticas; Brasil; Semi-árido; Integração de Políticas Públicas.

THE CHALLENGE OF INTEGRATING PUBLIC POLICIES FOR CLIMATE ADAPTATION IN THE BRAZILIAN SEMI-ARID REGION

ABSTRACT: The article discusses the challenges of public policy in promoting the governance of natural resources in the region of the São Francisco Sub-medium river, in particular the conflicting interactions between water, food, energy, and socioenvironmental security. The land use processes and the implementation of public policies are presented in a first section, focusing on energy projects and their interactions with the use of water resources and with productive and agrarian issues. The second section presents primary data on public investment in the region, which has been targeted at wind projects, and the inter-institutional interactions for implementing these resources. The third section discusses the risks presented by wind projects, in order to reproduce unequal investment patterns in the territory and increase socio-environmental 
vulnerability, despite the potential of these projects to promote the mitigation of climate change

KEYWORDS: Nexus Approach; Adaptation to Climate Change; Brazil; Semi-arid; Integration of Public Policies

\section{INTRODUÇÃO}

As projeções climáticas preveem importantes alterações nos padrões de temperatura e precipitação para os biomas brasileiros, podendo influenciar a disponibilidade e a utilização dos recursos dos quais dependem os meios de vida humanos (MAGRIN et al., 2014). Diante deste cenário, as respostas políticas e institucionais são indispensáveis à redução da vulnerabilidade das populações urbanas e rurais, influenciando o acesso aos recursos e a capacidade de respostas efetivas (BIGGS et al., 2014). Entretanto, a promoção de estratégias adaptativas requer abordagens mais integradas que permitam minimizar conflitos relacionados ao uso de recursos naturais e entre respostas políticas setorizadas, baseadas em mecanismos muitas vezes custosos em termos de compensações, externalidades e passivos (GIATTI et al., 2016).

Um episódio de seca entre 2012 e 2016 gerou uma série de impactos socioambientais e econômicos no semiárido nordestino, como a redução da produção agrícola, a perda significativa na pecuária, e a redução dos níveis de água nos reservatórios para abastecimento humano e dessedentação animal, e também para a geração de energia (DE NYS; ENGLE, 2014). A região do Submédio São Francisco, além de ser afetada pelas mudanças climáticas e estar diante de impactos relacionados ao projeto de transposição das águas do rio, foi historicamente marcada por desafios relacionados à lentidão da regularização fundiária, ao alagamento de extensas áreas por barragens, à implantação de programas público-privados de irrigação e à competição pelo uso das águas para diferentes finalidades (energia, agricultura, abastecimento urbano etc.). A região é hoje caracterizada por uma série de desigualdades e ocupada por áreas de agricultura irrigada e mecanizada, mescladas com agricultura de sequeiro e caprinovicultura extensiva (MMA, 2006).

Grandes projetos hidrelétricos inundaram áreas ao longo da bacia desde os anos 1950, gerando conflitos relacionados ao uso dos recursos hídricos, que foram majoritariamente alocados para a produção energética, em detrimento dos modos tradicionais de utilização como a pesca artesanal e a agricultura familiar. Mais recentemente, diante dos impactos da seca prolongada sobre as hidrelétricas, outras soluções vêm sendo propostas para aumentar a disponibilidade de energia, por exemplo, os projetos de produção eólica e solar. Assim como as hidrelétricas e os projetos de irrigação, os parques eólicos apresentam riscos sobre a ocupação desigual de terras e de alocação assimétrica de recursos no território. Apesar do seu potencial de redução de emissões de gases de efeito estufa, devem-se observar os padrões de desenvolvimento das políticas, para que sejam de fato integradas com outros setores, em prol da adaptação e mitigação às mudanças climáticas.

Neste contexto, o artigo discute os conflitos históricos e as perspectivas atuais para uma governança "transversal" dos recursos naturais na região do Submédio São Francisco, a partir da integração entre estratégias setoriais. Foram utilizados dados primários referentes à execução dos recursos públicos federais nos municípios da região e dados bibliográficos para caracterização dos processos de ocupação do território e de implementação de políticas públicas. A 
primeira seção apresenta os processos históricos, com foco nos projetos energéticos e suas interações com a utilização de recursos hídricos e com questões produtivas e agrárias. A segunda seção apresenta os dados primários de investimento público e as interações interinstitucionais para a execução destes recursos. Tais interações serão analisadas com suporte da metodologia de análise de redes sociais. Por fim, a terceira seção discute alguns dos riscos apresentados pelos projetos eólicos, no sentido de reproduzir os padrões desiguais de investimentos no território e aumentar a vulnerabilidade socioambiental, apesar do potencial destes projetos em promover a mitigação das mudanças climáticas.

\section{CONSIDERAÇÕES TEÓRICAS E METODOLÓGICAS}

A bacia do rio São Francisco, dividida em quatro regiões fisiográficas (Alto, Médio, Submédio e Baixo), é a terceira maior do país. Sua grande extensão é marcada por diferenças regionais do ponto de vista socioeconômico e ambiental. A região do Submédio (Figura 1) apresenta, segundo dados do IBGE, cerca de $16 \%$ da população residente na bacia, dos quais $40 \%$ são habitantes rurais. Grande parte da população urbana concentra-se nas aglomerações de Petrolina/Juazeiro e de Paulo Afonso. A região está inteiramente inserida no bioma Caatinga e corresponde a um espaço semiárido, que já vem sendo atingido por processos de desertificação, pela alteração no regime de chuvas e de secas, e que poderá ser gravemente afetada pelas mudanças climáticas (CBHSF, 2015; IPCC, 2014). O potencial do setor primário é considerado baixo, em comparação com as demais regiões, apresentando limitações de disponibilidade hídrica e alto risco de salinização do solo. Apenas $7 \%$ do volume total de produção agrícola da bacia ocorre nesta faixa (MMA; COBRAPE-PROJETEC, 2017).

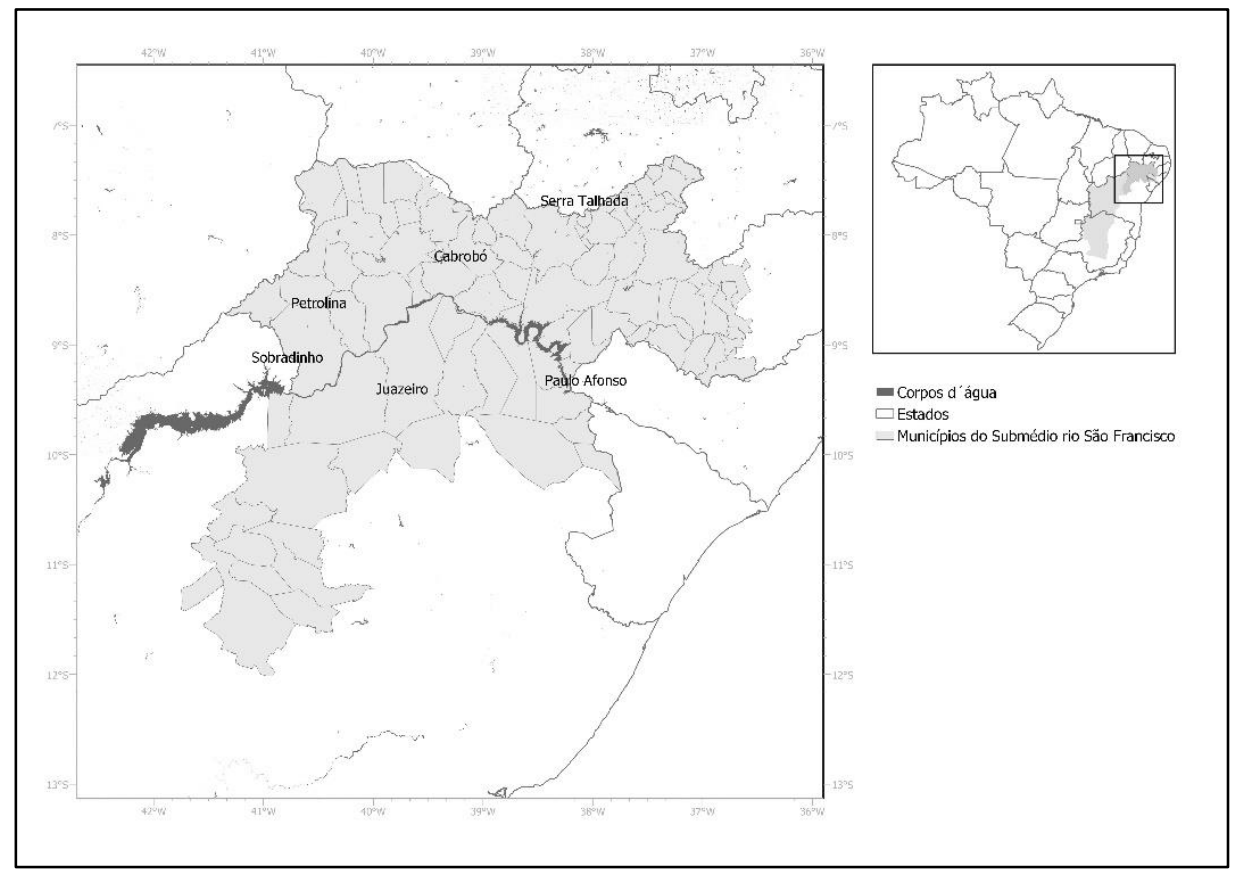

Figura 1- Localização da zona de estudo - Submédio rio São Francisco. Fonte: Autores 
As interrelações entre os setores hídrico, energético e agrícola observadas no território serão analisadas sob a ótica da "abordagem nexus". Esta baseia-se na premissa de que a ênfase limitada nas interfaces entre tais setores pode levar a intervenções contraditórias e ao uso ineficiente dos recursos naturais. Argumenta-se que estratégias exclusivamente setoriais podem aumentar as vulnerabilidades restringindo capacidades ou aumentando os riscos em outro local ou setor, e que as interações entre esses sistemas afetam sua disponibilidade (BIGGS et al., 2014; GIATTI et al., 2016; RASUL; SHARMA, 2016). As seguranças alimentar, energética e hídrica são, portanto, integradas em um único arcabouço analítico, cujo enfoque é o acesso a recursos importantes para o bem-estar humano e a moderação de impactos sobre sua disponibilidade e qualidade futuras (BIGGS et al., 2014).

Apesar da orientação prática destes trabalhos, sua aplicação se depara com uma série de desafios. Primeiramente, o processo de ocupação dos territórios e de implementação das políticas públicas pode seguir padrões muitas vezes divergentes, levando a conflitos entre os múltiplos objetivos e atores envolvidos. Outro desafio refere-se à tendência da literatura e das organizações internacionais em recomendar receitas muitas vezes burocráticas e soluções tecnológicas voltadas para o aumento da eficiência e para a regulação econômica do uso dos recursos naturais (ALLOUCHE; MIDDLETON; GYAWALI, 2014). Estudos mais críticos o consideram uma abordagem apolítica de gestão dos recursos naturais sendo que as soluções tecnológicas e tecnocráticas são consideradas insuficientes para responder a desafios societais tão complexos e interligados. Portanto, a governança representa um aspecto fundamental neste contexto (STIRLING, 2015; SWATUK; CASH, 2018).

Da mesma forma, as soluções tecnológicas desenhadas para mitigar as mudanças climáticas e os impactos ambientais não têm se mostrado suficientes para garantir a resiliência das populações mais vulneráveis, como será discutido ao longo do texto. Estratégias de mitigação podem inibir impactos positivos sobre a adaptação, quando os ganhos em sequestro ou redução de emissão de carbono levam a um aumento da vulnerabilidade de determinadas populações. Nesse sentido, alguns autores ressaltam a importância de haver consistência não só entre as iniciativas de mitigação e adaptação às mudanças climáticas e as demais políticas de desenvolvimento, mas também entre estes dois objetivos da política do clima (LOCATELLI et al., 2015).

Neste artigo, além das interdependências entre alimentos, energia e água, consideramos a relação destes setores com a segurança socioambiental. Dessa forma, as questões sociais, políticas, institucionais e de infraestrutura relacionadas ao acesso, disponibilidade e qualidade dos recursos essenciais de subsistência são mais explicitamente associadas às estratégias de adaptação às mudanças climáticas. Por fim, assim como Biggs et al. (2014), acrescenta-se ao arcabouço a variável climática, dada sua influência direta na segurança socioambiental das populações da região de estudo. A Figura 2 apresenta um esquema representativo da abordagem nexus, aplicada ao caso do Submédio São Francisco. 


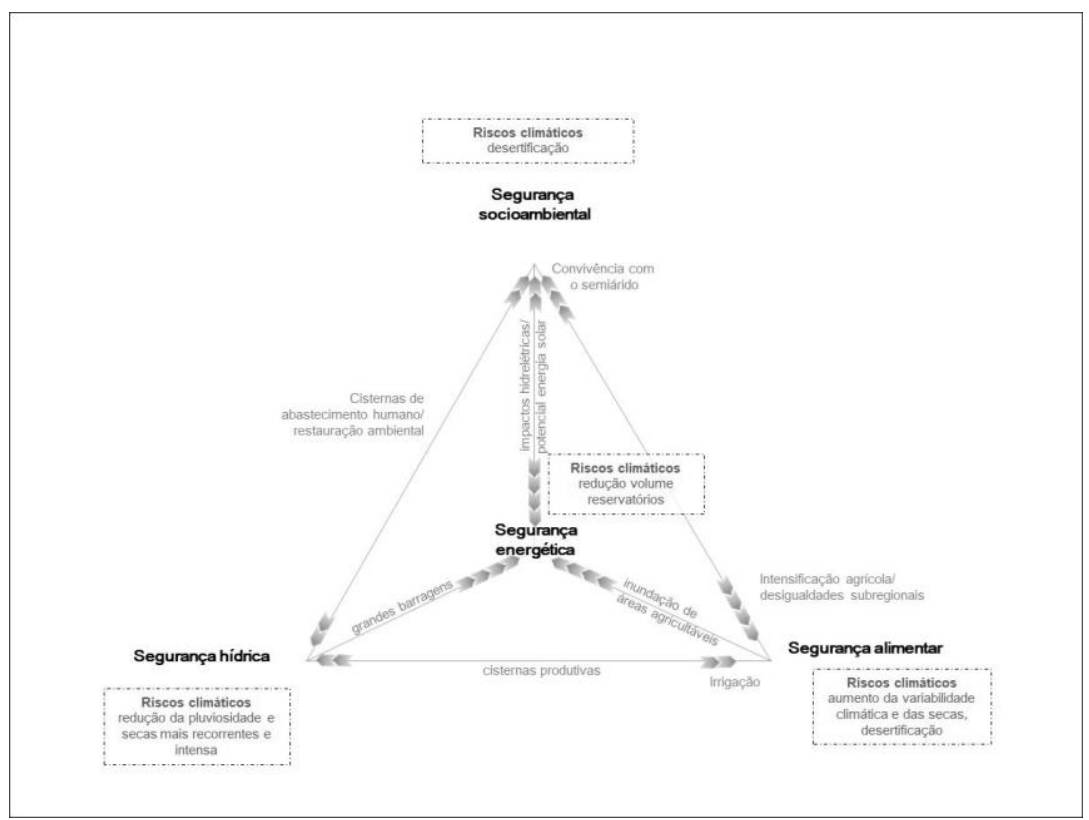

Figura 2 - Esquema da abordagem nexus aplicada ao caso do Submédio rio São Francisco. Fonte: adaptado de Milhorance \& Bursztyn (2019)

O artigo analisa as interfaces entre segurança alimentar, energética, hídrica, e socioambiental, a partir de três estratégias. Primeiro avalia o histórico de ocupação do Submédio São Francisco e de intervenções públicas e privadas nos sistemas considerados. Segundo, analisa os desafios atuais de gestão dos recursos naturais e o padrão de intervenções no território. Terceiro, alia a análise socio-histórica a uma análise das relações interinstitucionais atualmente relevantes na região. A análise de redes foi utilizada para facilitar a visualização das interações institucionais, com base no fluxo de recursos financeiros para o território. Esta considera dados de execução dos recursos federais por município do Submédio entre 2012 e 2016, período que caracteriza o último evento de seca. Para isto, foram utilizados dados primários do Portal da Transparência e um software de análise de redes sociais (Gephi).

Além do mapeamento das interações institucionais-financeiras, foram identificadas as ações federais que estão sendo implementadas no território. 0 volume de recursos por ação governamental implementada em cada município foi divido pela população prevista anual do município e o total de recursos alocados àquela ação na região do Submédio São Francsico. Este cálculo garante a comparação entre os recursos alocados nos três setores (águaenergia-alimentos) em cada município. Seu objetivo é fornecer um "retrato" do território no que se refere à distribuição das iniciativas de ação pública. Por fim, foram realizadas entrevistas com gestores das políticas identificadas a fim de completar a análise qualitativa. 


\section{O NeXo ÁguA-energia-Alimento EM PERspectiva histórica: FRAGMENTAÇÃO SETORIAL NO SUBMÉDIO SÃO FRANCISCO}

Além dos fatores de exposição climática observados na região, o processo histórico de uso e ocupação do território, bem como os padrões de intervenção pública, contribuíram para aumentar a vulnerabilidade socioambiental de suas populações. Tais padrões de uso e de ação pública desde a segunda metade do século XX têm sido amplamente abordados pela literatura acadêmica (BURSZTYN, 2008). Esta seção propõe uma breve releitura deste processo histórico, porém sob um ângulo inédito: o das interrelações entre setores e recursos essenciais aos meios de vida e ao bem-estar humanos água, energia e alimentos. A análise baseia-se na perspectiva de que as estruturas políticas, econômicas e sociais interferem na vulnerabilidade dos sistemas socioecológicos. Na linha proposta por Turner et al. (2003), diferentes sistemas apresentam distintas sensibilidades a distúrbios, o que está em parte relacionado às garantias de acesso aos recursos.

Partindo da questão do uso e do gerenciamento dos recursos hídricos, a região enfrenta uma série de desafios para garantia de acesso equitativo aos seus múltiplos usuários. Os planos de desenvolvimento para a bacia do rio São Francisco constituem um dos exemplos mais emblemáticos da fase de planejamento macrorregional desenvolvimentista, na forma de uma intensa atuação setorial e regional do governo federal, que prevaleceu entre os anos 1950 e 1970. Vale notar que o fenômeno da seca no semiárido orientou as intervenções durante toda trajetória de sua ocupação. O Departamento Nacional de Obras Contra as Secas (DNOCS) foi institucionalizado no início do século XX, ocupando-se da construção de reservatórios de água e de obras de infraestrutura (GUIMARÃES, 2010). Além disso, tais políticas e as demais analisadas nesta seção foram direcionadas, sobretudo, pelas elites locais, que se beneficiaram das transferências federais, das isenções fiscais e negociação das dívidas, traduzindo-se no avanço do clientelismo e na permanência dos detentores de poder (BURSZTYN, 2008).

A visão recente de gestão dos recursos hídricos da região tem apresentado mudanças, como o fortalecimento de uma perspectiva de "convivência com o semiárido" (em oposição à tradição de "obras contra a seca") e de usos múltiplos da água, que serão discutidas na próxima seção. No entanto, há fortes resquícios da lógica de que grandes investimentos em infraestrutura constituem as melhores opções para viabilizar o desenvolvimento. Sob esta perspectiva está o projeto de transposição do rio São Francisco. O ativismo desenvolvimentista com foco nos investimentos em infraestrutura era, em parte, inspirado pela percepção da necessidade de um big push - ou do apoio estatal por meio de investimentos coordenados para garantir a aceleração do crescimento econômico. Tal visão baseava-se na hipótese da industrialização como resultado do investimento simultâneo em setores-chave e complementares, buscando transformar a estrutura econômica de regiões menos desenvolvidas e permitindo a superação do ciclo de pobreza (poverty trap) (ROSENSTEIN-RODAN, 1943).

No caso brasileiro, esta perspectiva era orientada a investimentos considerados estratégicos para a industrialização do país, como eletricidade, petróleo e aço. Esta lógica baseada em grandes projetos de infraestrutura foi criticada, considerando-se os resultados contestáveis na redução das 
desigualdades regionais (EASTERLY, 2006). Além disso, ao contrário das políticas contemporâneas, as estratégias implementadas no Brasil dos anos 1960-70 foram concebidas e conduzidas num ambiente político autoritário, caracterizado pelo insulamento tecnoburocrático, pela tomada de decisões em arenas restritas e pela ausência de estudos de impacto ambiental.

No setor energético, a ótica das intervenções foi semelhante, fundada na execução de grandes projetos com foco na produção hidrelétrica. Neste setor, a Companhia Hidrelétrica do Vale do São Francisco (CHESF) e a Companhia de Desenvolvimento do Vale do São Francisco (Codevasf), ambas criadas na década de 1940, tiveram importância considerável. Nos anos 1980, a iniciativa privada foi incentivada a atuar nos lotes públicos de irrigação, o que contribuiu para o aumento da área irrigada, paralelamente à redução da capacidade de investimento do Estado (CASTRO, 2018). Uma série de autores questiona os impactos sociais destas intervenções que, apesar de terem sido positivos na geração de empregos, não teriam sido efetivos na melhoria das condições sociais no que tange à renda e à sustentabilidade nos vales férteis (BURSZTYN, 2008; CASTRO, 2018).

Apesar dos eventos de seca, a construção das usinas hidrelétricas foi tratada como prioritária para a região. Este enfoque foi reafirmado nos anos 1970, com o estabelecimento do II Plano Nacional de Desenvolvimento e após a crise internacional do petróleo. Ainda na década de 1970, deu-se início à construção da barragem de Sobradinho, o maior reservatório até então, com $4.214 \mathrm{Km} 2$ de extensão. Sua construção foi acompanhada pelo deslocamento de mais de 60 mil pessoas (LINS, 2011). Tanto o alagamento de terras (à montante) quanto as secas (à jusante) das barragens resultaram em conflitos de uso da água entre o setor elétrico, pesqueiro e agrícola, com populações locais afetadas especialmente no desenvolvimento da pesca, da agricultura de vazante e da irrigação de pequenas áreas (MMA, 2006).

O Banco do Nordeste do Brasil (BNB) e a Superintendência do Desenvolvimento do Nordeste (Sudene) foram instituições-chave no processo como um todo. A criação da Sudene foi baseada no debate encabeçado por Celso Furtado que defendia a elaboração de planos regionais de desenvolvimento, segundo uma perspectiva de que a disponibilidade hídrica não significava exclusivamente um problema climático (MMA, 2006). Com isso, a instituição se tornou uma referência para os esforços de planejamento macrorregional em outras regiões brasileiras. Diferentemente das demais superintendências, a Sudene foi criada num contexto democrático, o que refletiu a inclusão, em sua agenda inicial, de temas relacionados às questões agrárias e de programas voltados à criação de uma indústria nacional e de uma moderna infraestrutura econômica e social. Durante o regime militar, sua atuação se limitou às ações de estímulos fiscais e financeiros aos grandes empreendimentos industriais e agropecuários e à ampliação de infraestruturas (GUIMARÃES, 2010).

A aposta no uso da irrigação havia sido inspirada em certa medida no modelo de modernização agrícola observado nos Estados Unidos (MMA, 2006). Tais estratégias visavam promover o aumento da produtividade e da renda proveniente da atividade agropecuária, por meio de melhorias de insumos e uso de maquinários. Segundo esta perspectiva, a baixa produtividade da região era vista principalmente como de natureza tecnológica e não relacionada à 
distribuição desigual de terras (SANTANA et al., 2014). O processo de modernização agrícola também significou uma mudança no uso dos recursos hídricos, da produção predominantemente baseada no consórcio gado-algodãolavoura alimentar para a irrigação de projetos de mono-cultivo. A Codevasf teve papel atuante neste processo, por meio de duas frentes principais. Por um lado, organizando agricultores por meio do estabelecimento de lotes irrigados e da criação de cooperativas; por outro lado, incentivando a implantação do agronegócio por meio de projetos privados (AMORIM; ALMEIDA, 2015).

Os grandes projetos transformaram a paisagem e as condições socioeconômicas da região. A irrigação subsidiou a produção de culturas para o mercado interno e externo, sendo a exportação de frutas responsável pela consolidação do polo agroindustrial no território. Com o desenvolvimento de tais setores, houve um aumento do PIB dos municípios da bacia, porém não acompanhado pela distribuição da riqueza entre a totalidade da população (BARROS, 2007). Antes deste período, a agricultura sertaneja garantia a subsistência dos habitantes locais e de centros urbanos próximos, sendo concentrada em áreas mais elevadas e úmidas (SABOURIN; CARON, 2009). Apesar dos objetivos amplos dos projetos de irrigação, na área de Petrolina/Juazeiro, poucos agricultores foram de fato beneficiados. Muitos deles acabaram sofrendo perdas, devido à salinização do solo que é vulnerávelvel ao uso intensivo de água (AMORIM; ALMEIDA, 2015).

Portanto, apesar dos esforços no sentido de ampliar o desenvolvimento regional, observa-se que as políticas implementadas entre 1950 e meados dos anos 1970 não promoveram uma redução efetiva da desigualdade social. Somese a isso o fato de que na década seguinte observou-se a fragilização da política desenvolvimentista, fruto de uma crise fiscal e financeira do Estado (GUIMARÃES, 2010). Observou-se ainda um crescimento privado do setor energético, acompanhado pela perda de dinamismo de empresas públicas regionais. No que se refere ao setor agrícola, a lógica de redução da intervenção do governo no financiamento e na comercialização levou à perda de importância de instrumentos como o crédito oficial e a extensão rural, que haviam marcado o período anterior (SANTANA et al., 2014).

Apesar da valorização do exercício de planejamento regional e da perspectiva de complementaridade entre setores, esta complementaridade era basicamente macroeconômica e orientada para a criação de mercados. Este processo não levou em consideração as interfaces relacionadas aos setores e recursos essenciais aos meios de vida no território, como ao acesso equitativo e a qualidade destes recursos ao longo do tempo. Ele resultou em uma série de conflitos que se reproduzem até hoje, como será discutido na próxima seção.

\section{GRANDES PROJETOS HIDRELÉTRICOS NO SÃO FRANCISCO: REPRODUÇÃO DE CONFLITOS ANTIGOS}

Os padrões históricos de intervenção estatal e o processo de ocupação do território descritos na seção anterior resultaram em conflitos, não apenas relacionados ao uso dos recursos naturais, como entre as agendas políticas setoriais. Apesar deste resultado, muitos dos projetos atuais seguem a mesma lógica dos investimentos anteriores, porém num ambiente marcado pela redemocratização e pelo maior envolvimento de atores políticos, econômicos e 
sociais no processo de formulação das políticas públicas. Os grandes projetos de infraestrutura foram retomados como prioridade governamental nos anos 2000, porém sob influência de arenas políticas mais diversificadas. Além das transformações políticas e econômicas, as mudanças climáticas também agregam maior complexidade a este processo, atuando como fator agravante de divergências já existentes.

O uso dos recursos hídricos continua sendo foco de importantes tensões, apesar dos avanços institucionais após a criação da Política Nacional de Recursos Hídricos ${ }^{1}$ (PNRH), que reconhece a existência de conflitos entre usuários da água e estabelece instrumentos para garantir os seus usos múltiplos, priorizando o consumo humano e a dessendentação de animais em situação de escassez (Art. $1^{\circ}$ ). No entanto, a atual distribuição dos riscos de desabastecimento não tem sido equânime entre os usuários deste recurso. Além disso, em toda extensão do Submédio, a demanda por água é de pelo menos $20 \%$ da vazão mínima natural, o que caracteriza uma situação crítica de uso. Em algumas regiões há competição de uso entre agricultura irrigada, pecuária, geração de energia e abastecimento humano, como nas sub-bacias dos rios Paraopeba, das Velhas, Alto Preto, Alto Grande, Verde Grade, Salitre e Baixo São Francisco (MMA; COBRAPE-PROJETEC, 2017).

Com relação aos projetos de irrigação, alguns de seus impactos resultam, por exemplo, na contaminação dos solos, dos rios e dos mananciais subterrâneos, devido à utilização de agrotóxicos e fertilizantes químicos (MMA; COBRAPE-PROJETEC, 2017). Ademais, a deficiência dos sistemas de drenagem dos projetos de irrigação, aliada ao sobreuso da irrigação, tem sido associada ao aumento da salinização dos solos. Tais impactos levam a conflitos que são também agravados por episódios de seca e processos avançados de desertificação, como ocorre no núcleo de Cabrobó em Pernambuco e na região de Rodelas na Bahia, considerada uma zona particularmente vulnerável à erosão. Estes fenômenos erosivos foram acentuados por conta do desmatamento de matas ciliares, da irrigação por pivô central, do manejo inadequado dos solos e de seu revolvimento constante pela utilização intensiva de maquinário (CBHSF, 2015).

Além dos aspectos já mencionados, desequilíbrios entre a oferta e a demanda de água podem afetar a segurança alimentar e nutricional, levando a alterações na oferta de alimentos no nível local. Por exemplo, a vazão controlada do rio impede o alagamento cíclico de áreas para a pesca tradicional, a piscicultura e o cultivo de arroz em lagoas marginais, impactando a reprodução social e econômica das populações ribeirinhas. Vale também assinalar que o acesso à água de qualidade para consumo humano, que ainda constitui um desafio para a ação pública nacional, é particularmente problemático na região. A implementação de cisternas vem sendo considerada uma estratégia-chave para garantir este acesso (MDSA, 2017).

Porém, a maior parte dos conflitos de uso envolve a geração de energia, especialmente no que se refere à operação das barragens, coordenada pelo Operador Nacional do Sistema (ONS) e gerenciada pela CHESF. O rio São Francisco representa a principal fonte de geração de energia do Nordeste, o que

\footnotetext{
${ }^{1}$ Substitui o Código das Águas (Decreto no 24.643, de 10 de julho de 1934), que previa a categoria "águas particulares" (Art. 8). A concepção da PNRH é de que a água é um bem de uso comum.
} 
torna a matriz regional altamente dependente da situação hidrológica da bacia. Algumas das práticas de operação criticadas pelos usuários incluem a imprevisibilidade dos níveis de água nos diferentes trechos, devido às variações de vazões turbinadas pelas usinas, que afetam a navegabilidade e o abastecimento de alguns municípios, e a inversão do regime natural de cheias e estiagens, que altera as características dos ecossistemas (CBHSF, 2015).

Estes procedimentos têm derivado basicamente das prioridades de geração de energia e não de um acordo entre as instituições envolvidas na gestão da bacia, como ONS, CODEVASF e seus usuários (MMA; COBRAPEPROJETEC, 2017). No entanto, diante do longo período de estiagem, a Agência Nacional de Águas (ANA) tem buscado preservar os estoques mínimos nos reservatórios de Sobradinho e do Xingó $^{2}$, tornado evidente a existência de conflitos de uso dos recursos, que são frequentemente acompanhados por conflitos político-institucionais na gestão destes recursos.

A região do Submédio São Francisco alberga um rico leque de atores que atuam no gerenciamento e na utilização dos recursos naturais. A bacia está inserida num contexto político-institucional complexo, incluindo unidades federativas e instituições como a ANA, a CHESF, a CODEVASF, o ONS, a Embrapa, a Companhia de Pesquisas de Recursos Minerais (CPRM), a Fundação Nacional de Saúde (FUNASA), entre diversos outros entes, cada uma com suas atribuições gerindo o mesmo território. O Comitê da Bacia Hidrográfica do rio São Francisco (CBHSF) busca articular os diversos interesses, incluindo ainda os atores sociais. A Figura 3 ilustra um aspecto das interações interinstitucionais na região, particularmente o fluxo de recursos financeiros nos setores água, energia e alimentos.

As redes indicam o fluxo dos recursos federais transferidos entre as instituições com atuação regional (identificadas por círculos): quanto maior o círculo maior o volume de recursos e de interações com outras instituições. As linhas de financiamento são identificadas por setores (tons de verde para agricultura; tons de azul para recursos hídricos/saneamento; tons de vermelho para energia). O esquema é simplificado e considera apenas as interações baseadas no fluxo de financiamento para implementação das políticas, não considerando outros aspectos como regulamentação, interações informais ou participação conjunta em conselhos.

\footnotetext{
${ }^{2}$ A primeira dessas medidas foi a redução da descarga mínima ambientalmente aceitável de restrição à jusante da barragem de Sobradinho de 1.300 para $600 \mathrm{m3} / \mathrm{s}$ (Resolução no 742, de 24 de abril de 2017). No entanto, esta mudança poderia ocasionar impactos sobre seus serviços socioambientais (CBHSF; AGB PEIXE VIVO, 2013), incluindo a intrusão salina que já se observa no Baixo São Francisco. A segunda estratégia foi o estabelecimento do "Dia do Rio" (Resolução no 1.043, de 19 de junho de 2017), com restrições semanais durante seis meses à captação de água, exceto para o abastecimento humano e dessedentação animal.
} 


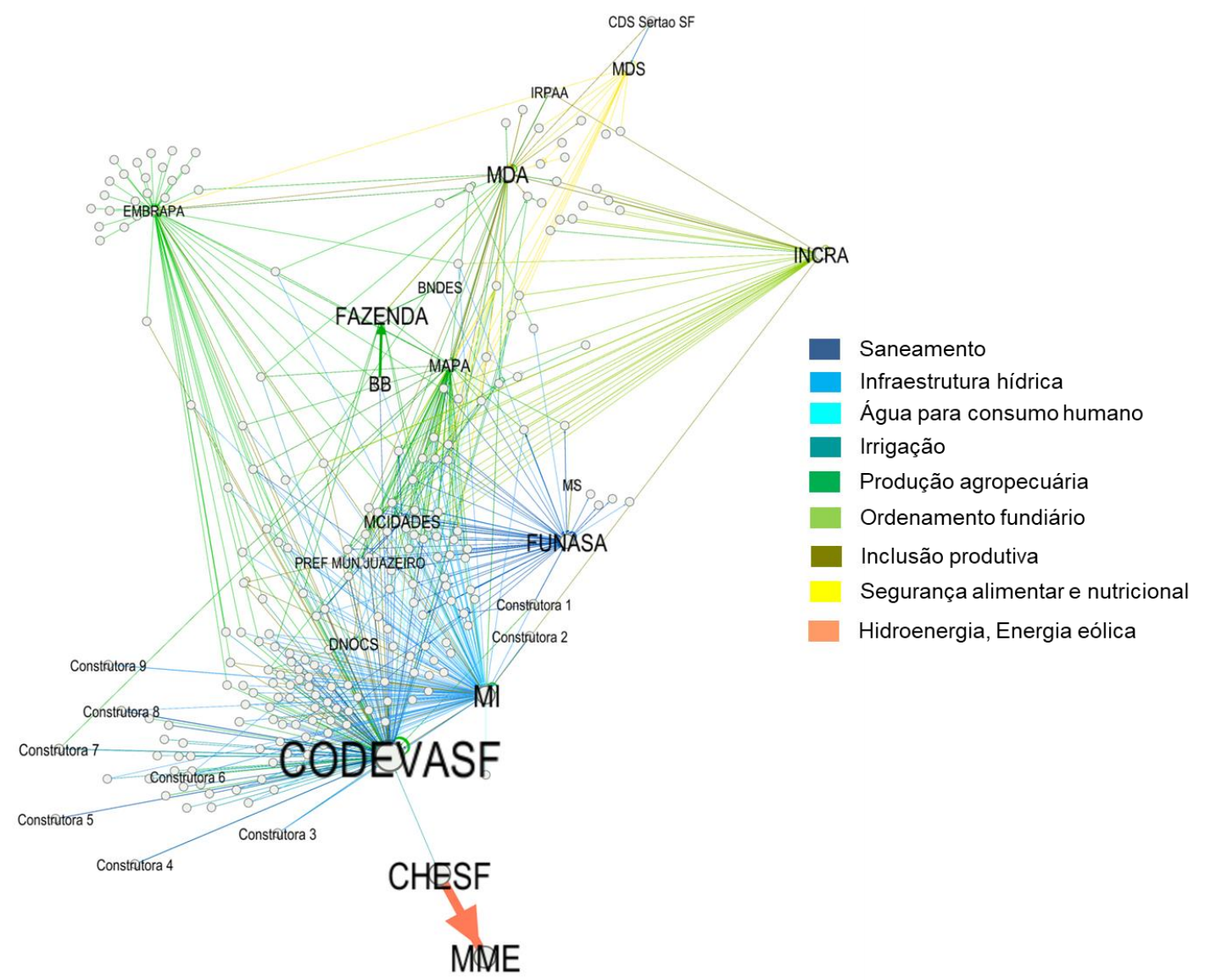

Figura 3 - Fluxo de recursos financeiros do governo federal (2012-2016) relacionados ao nexo água-energia-alimentos no Submédio São Francisco. Fonte: elaborado pelos autores com dados do Portal da Transparência

Nota-se a importância de atores como o Ministério da Integração (MI) e a própria Codevasf já citada anteriormente, que estão integrados num arranjo institucional-financeiro bastante relevante nas obras hídricas. Vale assinalar que a Codevasf orientou o estabelecimento de perímetros irrigados, canais de irrigação e barragens com foco na modernização da agricultura e nas ações de resposta às secas. De acordo com representantes da companhia em Petrolina, houve grande mudança no perfil dos atores envolvidos na implementação dos perímetros irrigados ao longo do tempo. Apenas cerca de $1 \%$ dos irrigantes corresponde atualmente a agricultores familiares ou assentados. Segundo relato, o perfil dos produtores selecionado para instalação nos novos perímetros de Pontal Sul e Norte é principalmente de técnicos.

Paralelamente, a Codevasf tem ampliado sua atuação para além da irrigação, incluindo ações de apoio à inclusão produtiva no sequeiro e participação no projeto de revitalização do rio São Francisco. Arranjos produtivos foram estimulados nos eixos de apicultura, caprinovinocultura, e produção de leite. Tais ações receberam apoio financeiro do programa federal Rota do Cordeiro, coordenado pelo MI. 
Por outro lado, o MI vem atualmente liderando uma mudança de paradigma com base em uma gestão proativa da seca, a partir da identificação das vulnerabilidades e da formulação de instrumentos de monitoramento, de prevenção e de convivência com a seca (DE NYS; ENGLE, 2014). No entanto, a estratégia do ministério de distribuição de cisternas de polietileno tem sido criticada por organizações da sociedade civil, reunidas em torno da Articulação do Semiárido (ASA), dado o baixo potencial deste modelo de cisternas e de distribuição para a geração de renda local e o engajamento das comunidades nos processos de implementação. Segundo membros da ASA, a instalação das cisternas de placa no âmbito do programa Uma Terra Duas Águas é acompanhada por discussões coletivas e capacitação sobre temas relevantes para a comunidade, o que não ocorre no processo capitaneado pelo MI. Diferentemente, segundo representantes da Codevasf, a cisterna de placa demanda maiores investimentos em manutenção por não ser resistente às variações térmicas, o que é questionado por representantes da ASA.

A Figura 3 ainda mostra diferentes núcleos envolvidos na promoção da produção agropecuária e da segurança alimentar e nutricional. Estes se encontram desarticulados do ponto de vista institucional e de canalização dos recursos. A Embrapa é a instituição chave na produção de tecnologias agrícolas, porém esta agenda está pouco articulada às demais do setor rural. Por exemplo, uma série de fatores limitam o acesso ao crédito voltado para a transformação de sistemas produtivos, como o programa agricultura de baixo carbono e o Pronaf verde (taxas poucos competitivas, burocracia e fatores técnicos) (OBSERVATÓRIO ABC, 2017). Além destes, a dificuldade de se incluir certas opções tecnológicas nas possibilidades de financiamento e a limitação da assistência técnica foram mencionadas por entrevistados como fatores centrais. A necessidade de maior diálogo entre as instituições de produção e validação de tecnologias como a Embrapa e as agências financeiras foi citada como forma de se promover o aumento do desembolso destas linhas "verdes".

O Ministério do Desenvolvimento Agrário (MDA) e o Ministério do Desenvolvimento Social (MDS) mostraram-se atuantes nas agendas de inclusão produtiva e de segurança alimentar, interagindo de maneira estreita com atores da sociedade civil, como o Instituto Regional da Pequena Agropecuária Apropriada (IRPAA). O MDA e o MDS têm sido politica e institucionalmente enfraquecidos desde 2016, após o impeachment da presidente Dilma Rousseff, o que também impactou a promoção do paradigma de convivência com a seca. A publicação de editais para a instalação de cisternas de placa, frequentemente acompanhadas por assistência técnica, representa uma das principais estratégias de operacionalização deste paradigma. Vale ainda ressaltar a importância deste tipo de arranjo institucional para a disseminação de práticas agroecológicas na agricultura de sequeiro.

Além destas, o Ministério da Agricultura (MAPA) apareceu em uma posição mais central da rede institucional, o que mostra maior grau de interações com as demais agendas, inclusive de gestão hídrica relacionada aos projetos de irrigação. Este ministério interage de forma mais estreita com as instituições financeiras responsáveis pelo crédito rural.

Por fim, a agenda energética aparece completamente desconectada do arranjo. Portanto, apesar dos altos níveis de investimentos concentrados neste setor e do alto grau de conflitos que ele engendra ainda nos dias de hoje, sua 
articulação do ponto de vista institucional-financeiro é baixa. Este aspecto contribui para reduzir a capacidade de negociação e planejamento integrado com os demais setores e será discutido na próxima seção.

A Figura 4 foi elaborada com base no volume proporcional de recursos públicos investidos em cada setor e em cada município. Pode-se observar a concentração espacial de agendas como a de energia, estabelecida basicamente na região de Sobradinho, Petrolina e Paulo Afonso, que inclui não apenas os investimentos em energia hidrelétrica como em energia eólica. Esta região é, entretanto, a que apresenta maior déficit se considerada a demanda/capacidade de retirada média anual da bacia. Ao norte da região, onde a precipitação média anual é considerada baixa, os principais investimentos são relacionados à segurança alimentar e nutricional. No entanto, em regiões mais críticas no que se refere aos processos de desertificação, como o núcleo de Cabrobó, estes investimentos são proporcionalmente menores. Portanto, a falta de articulação política e setorial se observa igualmente na distribuição territorial dos investimentos públicos.

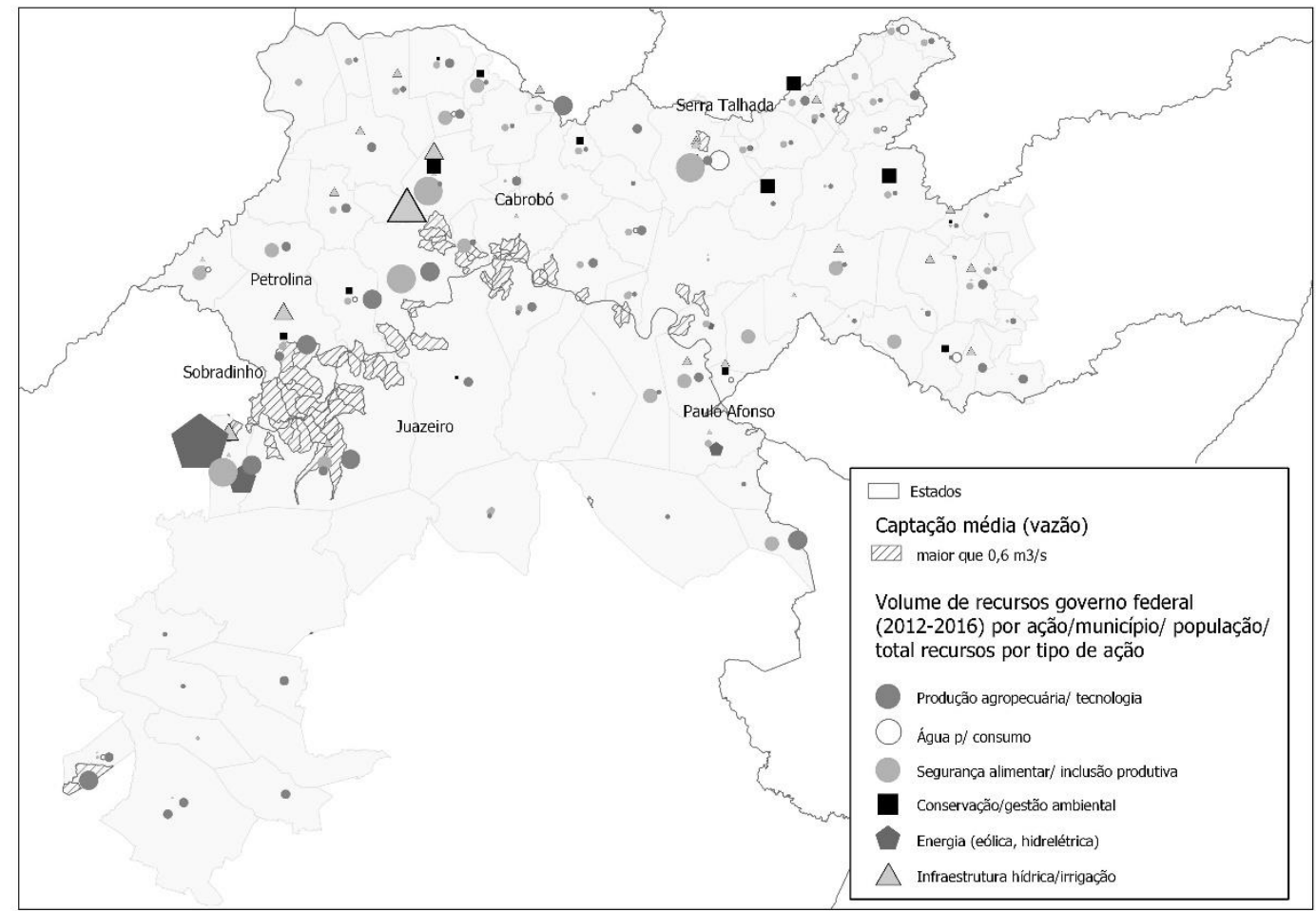

Figura 4 - Investimentos do governo federal (2012-2016) por ação e município do Submédio São Francisco. Fonte: elaborado pelos autores com dados do Portal da Transparência

\section{NOVAS FONTES ENERGÉTICAS, NOVOS CAMINHOS?}

O caso do Submédio São Francisco mostra que a reprodução de intervenções baseadas em grandes obras de infraestrutura sem capilaridade no território e sem articulação com os demais setores-chave para os meios de vida locais tem contribuído para a renovação dos conflitos de uso dos recursos 
naturais. Isso ressalta a importância das interfaces das ações de mitigação/adaptação, bem como do nexo água-energia-alimentos. Estas não são as únicas interações relevantes, sendo que aspectos como a salinização dos solos e a falta de saneamento geram impactos significativos sobre os indicadores de saúde. Porém trata-se de uma combinação considerada estruturante para a região analisada, sobretudo diante dos riscos associados às mudanças climáticas nesse território.

Mais do que uma abordagem normativa e baseada na eficiência do planejamento macrorregional, a busca pela coerência entre as intervenções estatais e as estratégias de uso dos recursos é resultado das dinâmicas de negociação e conflito entre os atores interessados no que se refere à utilização dos recursos naturais (ADELLE; RUSSEL, 2013). As interações institucionais e políticas, bem como a contestação em torno da construção do poder, são, portanto, peças fundamentais na compreensão deste processo. A explicação das divergências entre objetivos das políticas públicas encontra-se muitas vezes em aspectos históricos, políticos e institucionais mais profundos, que vão além do debate sobre eficácia política. As intervenções históricas nas obras contra a seca e na produção de energia a partir da construção de hidrelétricas foram reproduzidas pelas elites locais em colaboração com o governo federal, porém resultaram em maior vulnerabilidade para grande parte das populações do Submédio.

Mais recentemete, diante do cenário de déficit hídrico e variabilidade climática, a produção de energia hidrelétrica na região tem ficado comprometida. Por exemplo, o reservatório de Sobradinho chegou a menos de 20\% do total do volume em 2015 e 2016 (Figura 5). Diante disso, a tendência tem sido a imposição de restrições operacionais, com acréscimo dos custos econômicos e socioambientais. Neste contexto, outras fontes de energia têm se expandido na região, especialmente a geração em usinas termelétricas e em parques de geração eólica (Figura 6 ). O Brasil tem um dos maiores mercados de energia eólica do mundo (ABEEÓLICA, 2016), com o Nordeste apresentando potencial que se sobrepõe às demais regiões do país, em função de sua posição geográfica e condições climáticas. Um grande marco nas políticas públicas para este setor foi a instituição do Programa de Incentivo às Fontes Alternativas de Energia (Proinfa), criado em 2002. O programa apostava no investimento estrangeiro direto e estabelecia metas de conteúdo local mínimo para os empreendimentos. Porém a necessidade de se constituir um mercado rápido levou ao abandono de tais exigências e, a partir de 2009, a proliferação de leilões acelerou o processo (NASCIMENTO, 2015). 


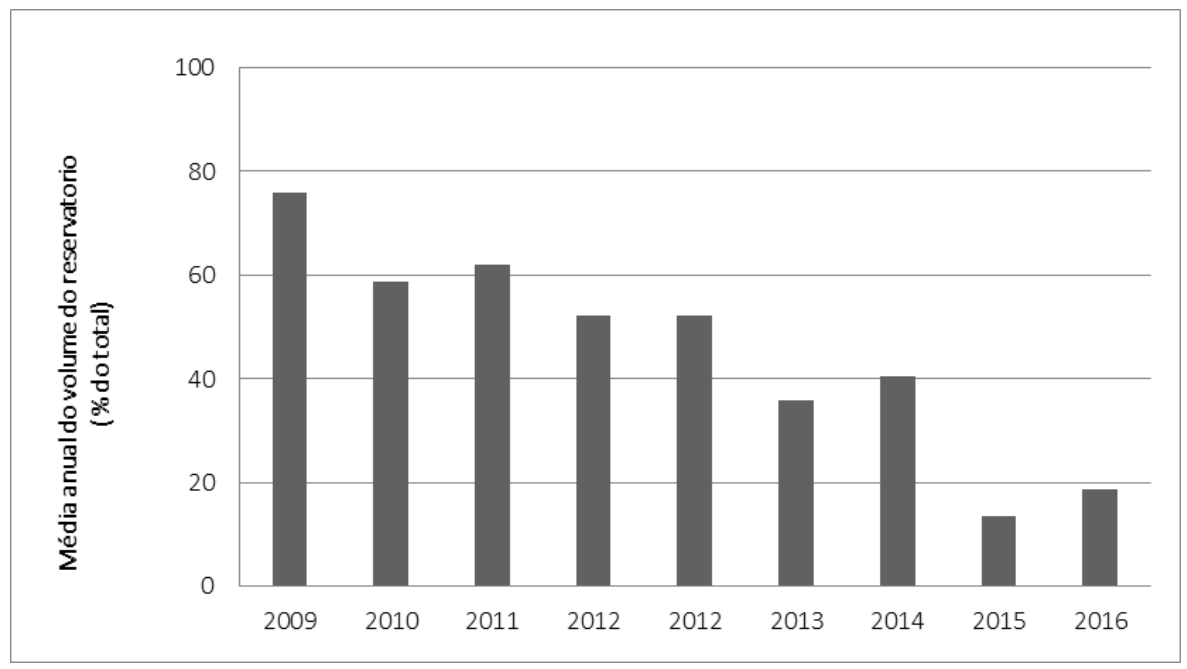

Figura 5 - Volume útil do reservatório de Sobradinho, entre 2009 e 2016. Fonte: Base de dados ONS (2017).

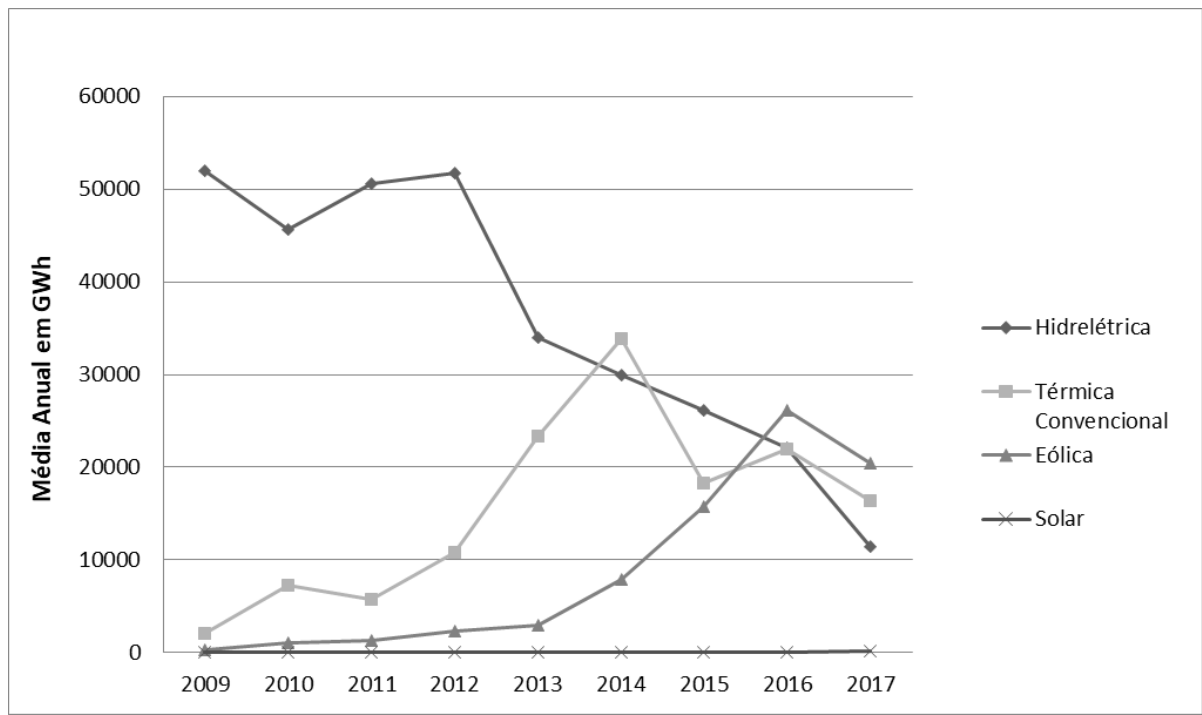

Figura 6 - Produção de Energia Hidráulica, Térmica, Eólica e Solar no Nordeste, entre 2009 e 2016. Fonte: Base de dados ONS (2017).

O desenvolvimento de fontes de geração eólica tem sido visto como um pontencial nos planos de expansão e operação do setor para o atendimento do subsistema Nordeste (EPE, 2017). O interesse pela exploração desses recursos é notado através da grande quantidade de empreendimentos em operação, construção e outorga pela Agência Nacional de Energia Elétrica (GONDIM; SANTOS, 2013). Outro ponto que favorece esta fonte é o fato de a geração eólica ser maior no período de menor volume dos reservatórios (SIMAS; PACCA, 2013). Na Bacia do São Francisco, entre Minas Gerais e o Submédio São Francisco, há grande potencial de geração, com destaque para algumas regiões da Bahia (MMA; COBRAPE-PROJETEC, 2017).

Segundo dados da CHESF, só no Submédio prevê-se a produção de 500 MW, com os complexos Eólicos de Sento Sé I, Sento Sé II e Sento Sé III e o 
Complexo de Casa Nova (CHESF, 2016). Também se prevê a construção do Complexo eólico de Sobradinho, ocupando uma área de mais de 1500 hectares. Esses três municípios estão passando novamente por grandes mudanças, resultantes da instalação de grandes projetos de produção energética. A própria CHESF informou em entrevista a percepção de que a energia hidrelétrica tem se tornado custosa em termos econômicos e socioambientais na região e que os empreendimentos eólicos geram menores impactos.

Assim como a energia hidrelétrica, a energia eólica é reconhecida como uma fonte alternativa de energia e uma forma de mitigação das mudanças climáticas. Apesar do seu potencial ambiental e econômico, os parques eólicos têm gerado debate acerca dos reais benefícios que podem trazer para as comunidades onde estão instalados. Alguns autores defendem que sua instalação poderá contribuir para o desenvolvimento de comunidades rurais no interior do Nordeste (SIMAS; PACCA, 2013). Porém, como discutido anteriormente, as políticas que incidiram e incidem na região têm se mostrado desintegradas do ponto de vista setorial e insuficientes para a superação dos desafios socioeconômicos e dos conflitos de uso dos recursos naturais locais. A chegada dos parques eólicos, além de potencialmente seguir o mesmo padrão de intervenção, traz desafios adicionais para o alcance destes objetivos.

Um dos aspectos é a grande produção de ruído e poeira, podendo afetar as condições locais de bem-estar e até problemas de saúde. Outro aspecto apontado por entrevistados do setor eólico baiano refere-se ao potencial de geração de empregos. A implantação de usinas gera empregos para as populações locais, mas a duração destes empregos costuma se limitar ao período de instalação (em média 18 meses) e são frequentemente voltados para a população masculina. Após esse período, a demanda é significativamente reduzida, limitando-se a vagas mais especializadas, raramente preenchidas por pessoas da região. Durante o período de operação, os parques eólicos trazem uma renda complementar aos donos de propriedades rurais, geralmente agricultores ou pecuaristas, que arrendam suas terras para as empresas que operam as usinas, com contratos que duram em média de 20 a 30 anos. Contudo, em alguns casos, as empresas recebem concessão de terras que pertencem a posseiros e a comunidades tradicionais invisíveis aos olhos do Estado, tais como os fundos de pasto (MORIMURA, 2015).

Outra questão refere-se à contradição de que algumas comunidades que abrigam as usinas não têm acesso à energia elétrica. Isto ocorre normalmente por conta da indisponibilidade de linhas de transmissão. Portanto, a utilização da energia eólica na região depende também da construção de novas linhas de transmissão e de evolução na questão da eficiência energética (MMA; COBRAPEPROJETEC, 2017). Por enquanto, as linhas existentes atendem principalmente aos grandes centros urbanos. Portanto, os impactos do setor não se dão apenas na produção de energia, mas também na sua distribuição. Ao mesmo tempo em que o potencial energético gerado pode ampliar a produção e a produtividade agropecuária em diversas escalas, tais atividades necessitam ser complementadas com políticas de regularização fundiária e de apoio aos agricultores familiares e comunidades tradicionais.

A energia solar, por outro lado, tem sido promovida por meio da geração distribuída com painéis fotovoltaicos. Diferentemente da energia eólica, a capacidade instalada fotovoltaica no Brasil ainda é irrisória, baseada em 
instalações off-grid, não conectadas à rede nacional. O Programa Nacional de Universalização do Acesso e Uso de Energia Elétrica (Luz para Todos - 2003) tem promovido esta fonte e tem-se observado uma redução significativa dos custos e do tempo de conexão de micro e minigeradores (NASCIMENTO, 2015). Apesar dos desafios operacionais e econômicos ainda existentes, este modelo apresenta uma alternativa mais sustentável à lógica estruturante de investimentos concentrados em grandes obras de infraestrutura e seu desenvolvimento tem sido levantado como estratégia de redução da pobreza (MMA; COBRAPE-PROJETEC, 2017).

Alguns analistas defendem inclusive a possibilidade de se aproveitar 0 potencial solar produzido em pequenas propriedades para distribuir a energia para a rede nacional. Segundo o pesquisador Paulo Nobre, esta opção seria mais rentável que a própria agricultura no semiárido (IPEA, 2017). No entanto, argumenta-se que esta estratégia poderia ser considerada em combinação com as políticas de apoio à produção familiar e à segurança alimentar e nutricional, e não como substituta. Trata-se justamente de uma oportunidade de se articular os eixos de mitigação e adaptação às mudanças climáticas, dado o potencial de inclusão social desta tecnologia. Este assunto merece maior discussão, que não cabe a este artigo.

Portanto, determinadas medidas de mitigação às mudanças climáticas podem gerar impactos negativos do ponto de vista da sua adaptação. Os empreendimentos hidroelétricos seguem um padrão de intervenção baseado em grandes projetos que geraram impactos socioambientais importantes e que vêm sendo agravados com o aumento da variabilidade climática. Os projetos eólicos têm mostrado potencial econômico e menores impactos socioambientais, tornando-se uma estratégia relevante para os operadores energéticos da região. No entanto, o foco nos grandes empreendimentos e a falta de uma institucionalidade que defina obrigações e benefícios destes projetos em relação às populações locais (p.ex. remuneração, aspectos fundiários, tipos de contrato e cancelamento), pode gerar novos desafios socioambientais. Por fim, pequenos projetos de energia solar têm sido promovidos pela academia e atores políticos como uma forma de garantir o acesso das populações locais à energia, gerando renda e impactos menores.

Tais cenários devem ser avaliados com base nas distintas realidades territoriais e nas relações políticas e institucionais locais, mas também com base na interface entre o setor energético e outros setores, buscando interações menos conflituosas entre segurança alimentar, energética, hídrica e socioambiental. De acordo com o próprio Painel Intergovernamental sobre Mudanças Climáticas, as políticas de adaptação e de mitigação, isoladamente, não são suficientes, o que requer respostas integradas destas iniciativas com outros objetivos sociais, em todas as escalas (IPCC, 2014). No entanto, este artigo mostrou que a prática de tal recomendação não é trivial e esbarra em características ambientais locais, além de disputas políticas, institucionais e econômicas características de cada região envolvida neste esforço.

\section{CONCLUSÃO}

A abordagem nexus mostrou-se útil para análise das dinâmicas sociais e políticas que influenciam o acesso e o uso dos recursos naturais. Ao enfatizar as 
interfaces entre estes recursos e os setores de ação pública, o arcabouço proporciona novas leituras de processos históricos conhecidos, com potencial de contribuir para o desenvolvimento de estratégias que minimizem as vulnerabilidades locais e regionais, reduzindo os riscos associados a ações setorizadas. No entanto, um aspecto desafiador deste arcabouço é sua tendência a resultar em propostas normativas com foco no aumento da eficiência na coordenação dos investimentos, ou nas respostas tecnológicas como solução dos conflitos de uso.

Como discutido neste artigo, a busca pela coerência entre as intervenções estatais e as estratégias de uso dos recursos é resultado das dinâmicas de negociação e conflito entre os atores interessados nos desafios, prioridades e oportunidades de desenvolvimento. Este é, por exemplo, o caso do debate sobre a vazão do rio São Francisco para os usos múltiplos da água, no âmbito do Comitê de Bacias. E, a explicação dos resultados contraditórios entre determinadas intervenções públicas e privadas no território está muitas vezes relacionada a aspectos históricos, políticos e institucionais, como no caso da prioridade dada aos grandes projetos de geração de energia que orientaram os objetivos de planejamento regional.

O mesmo desafio se aplica à questão da integração entre os objetivos de mitigação e adaptação às mudanças climáticas. Diante da seca prolongada e dos impactos desta sobre as hidrelétricas, os projetos de produção de energia eólica e solar têm sido propostos como solução para o aumento da disponibilidade energética. Tais projetos são valorizados por contribuírem para a redução das emissões de gases de efeito estufa. No entanto, no caso das usinas eólicas, da mesma forma que as hidrelétricas e os projetos de irrigação, sua instalação apresenta riscos no que tange à ocupação desigual de terras e de alocação assimétrica de recursos públicos no território. Além disso, os impactos sobre os meios de vida local e a baixa capacidade destes empreendimentos em distribuir eletricidade geram um debate sobre seu potencial em promover 0 desenvolvimento regional. Tais padrões são contraditórios aos objetivos de adaptação às mudanças climáticas e de redução das vulnerabilidades locais. A integração entre estes dois objetivos (mitigação e adaptação) depende de esforços políticos que requerem um olhar mais integrado sobre o território e que inclua as populações residentes nos processos de consulta e planejamento.

Portanto, novas dinâmicas de negociação serão necessárias neste contexto de mudanças políticas e climáticas, e diante da transposição do rio São Francisco, que incluirá novos atores, interesses e desafios, complexificando a governança dos recursos da bacia. Pode-se, portanto, afirmar que as estruturas políticas, econômicas e sociais interferem na vulnerabilidade dos sistemas socioecológicos. Se por um lado as intervenções públicas podem contribuir para aumentar a capacidade adaptativa das populações face às mudanças ambientais, tais intervenções também podem aumentar a sensibilidade do sistema sócio-ecológico dependendo do resultado de suas interações.

\section{REFERÊNCIAS BIBLIOGRÁFICAS}

ABEEÓLICA. Boletim anual de geração eólica 2016. São Paulo: Associação Brasileira de Energia Eólica, 2016. Disponível em: <http://www.abeeolica.org.br/wp- 
content/uploads/2017/05/424_Boletim_Anual_de_Geracao_Eolica_2016_Alta.pd $f>$.

ADELLE, C.; RUSSEL, D. Climate Policy Integration: a Case of Déjà Vu?: Climate Policy Integration: A case of déjà vu? Environmental Policy and Governance, v. 23, n. 1, p. 1-12, jan. 2013.

ALLOUCHE, J.; MIDDLETON, C.; GYAWALI, D. Nexus Nirvana or Nexus Nullity? A dynamic approach to security and sustainability in the water-energy-food nexus: Water and the Nexus. Brighton: STEPS Centre, 2014.

AMORIM, F. C. L.; ALMEIDA, M. . A política de capitalização latifundiária da reforma agrária no Vale do Rio São Francisco: um estudo no projeto de assentamento Catalunha (PE, Brasil, 1980-1998). Rev. Hist. UEG, v. 4, p. 8397, 2015.

BARROS, E. R. Arranjos Socioprodutivos da Agricultura Familiares e Adaptação a uma Dinâmica Territorial de Desenvolvimento. Tese de DoutoradoFlorianopolis: Universidade Federal de Santa Catarina, Centro de Ciências da Educação. Programa de Pós-graduação em Educação., 2007.

BIGGS, E. M. et al. Environmental livelihood security in Southeast Asia and Oceania: a water-energy-food-livelihoods nexus approach for spatially assessing change. White paper. [s.l.] International Water Management Institute (IWMI)., 2014. . Acesso em: 12 mar. 2017.

BURSZTYN, M. O poder dos donos: Planejamento e clientelismo no Nordeste. 3a edição ed. Rio de Janeiro: Garamond, 2008.

CBHSF. Plano de recursos hídricos da Bacia Hidrográfica do rio São Francisco: diagnóstico da dimensão técnica e institucional: Caracterização da bacia hidrográfica - parte I. Salvador: Comitê da Bacia Hidrográfica do rio São Francisco, 2015.

CBHSF; AGB PEIXE VIVO. Usos múltiplos na bacia hidrográfica do rio São Francisco - Políticas e prioridades. Salvador: Comitê da Bacia Hidrográfica do rio São Francisco, 2013.

CHESF. Sistema Chesf Eólica. Disponível em: <https://www.chesf.gov.br/SistemaChesf/Pages/FontesRenovaveis/Eolica.aspx> . Acesso em: 4 out. 2017.

DE NYS, E.; ENGLE, N. L. Convivência com o Semiárido e Gestão proativa da seca no Nordeste do Brasil: Uma nova Perspectiva. [s.l.] The World Bank, 1 maio 2014. . Acesso em: 18 abr. 2017.

EASTERLY, W. Reliving the 1950s: the big push, poverty traps, and takeoffs in economic development. Journal of Economic Growth, v. 11, n. 4, p. 289-318, 7 dez. 2006.

EPE. Plano Decenal de Expansão de Energia 2026. Brasília: Ministério de Minas e Energia, 2017.

GIATTI, L. L. et al. O nexo água, energia e alimentos no contexto da Metrópole Paulista. Estudos Avançados, v. 30, n. 88, p. 43-61, dez. 2016.

GONDIM, D. C.; SANTOS, R. C. C. DOS. As moderas fontes renovaveis de energia e o desenvolvimento do Nordeste brasileiro: o problema da ausência de 
receitas não tributarias pela exploração dos potenciais eolico e solar. Revista de Direito UNIFACEX, v. 4, n. 1, 2013.

GUIMARÃES, A. Antecedentes e evolução do planejamento territorial no Brasil. In: GUIMARÃES, L.; BACELAR, T. (Eds.). . Políticas de desenvolvimento territorial rural no Brasil: avanços e desafios. Série Desenvolvimento rural sustentável. Brasília: Instituto Interamericano de Cooperação para a Agricultura-IICA, Representação do IICA no Brasil, 2010. p. 46-80.

IPCC. Climate Change 2014: Synthesis Report. Contribution of Working Groups I, II and III to the Fifth Assessment Report of the Intergovernmental Panel on Climate Change. Geneva: Intergovernamental Panel of Climate Change, 2014.

IPEA. Potencial solar pode inserir o Nordeste na geração energética do país e desenvolver a região. Disponível em: <https://www.ipea.gov.br/portal/index.php?option=com_content\&view=article\& id=29918\&catid=24\&Itemid=7> . Acesso em: 20 ago. 2017.

LINS, R. C. Energia hidrelétrica do Nordeste. Ciência \& Trópico, v. 1, n. 1, 2011.

LOCATELLI, B. et al. Integrating climate change mitigation and adaptation in agriculture and forestry: opportunities and trade-offs: Integrating climate change mitigation and adaptation in agriculture and forestry. Wiley Interdisciplinary Reviews: Climate Change, v. 6, n. 6, p. 585-598, nov. 2015.

MAGRIN, G. . et al. Central and South America. In: BARROS, V. R. et al. (Eds.). . Climate Change 2014: Impacts, Adaptation, and Vulnerability. Part B: Regional Aspects. Contribution of Working Group II to the Fifth Assessment Report of the Intergovernmental Panel on Climate Change. Cambridge: Cambridge University Press, 2014.

MDSA. Plano Nacional de Segurança Alimentar e Nutricional - PLANSAN (20162019). Brasilia: Ministério do Desenvolvimento Social e Agrário, 2017.

MMA. Caderno da Região Hidrográfica do São Francisco. Brasília: Ministério do Meio Ambiente, Secretaria de Recursos Hídricos, 2006.

MMA; COBRAPE-PROJETEC. Atualização e Complementação do Diagnóstico do Macrozoneamento Ecológico-Econômico da Bacia Hidrográfica do Rio São Francisco: Relatório da Análise Integrada e Crítica sobre a Situação Atual da BHSF. Brasília: Ministério do Meio Ambiente, 2017.

MILHORANCE, C.; BURSZTYN, M. Climate adaptation and policy conflicts in the Brazilian Amazon: Prospects for a Nexus+ approach. Climatic Change, forthcoming 2019.

MORIMURA, M. Governança de Recursos de Base Comum e capacidade adaptativa de comunidades de Fundos de Pasto. Tese de Doutorado-Brasilia: Universidade de Brasília, 2015.

NASCIMENTO, P. A. M. M. Considerações sobre as indústrias de equipamentos para produção de energias eólica e solar fotovoltaica e suas dimensões científicas no Brasil. 2015.

RASUL, G.; SHARMA, B. The nexus approach to water-energy-food security: an option for adaptation to climate change. Climate Policy, v. 16, n. 6, p. 682-702, 17 ago. 2016. 
ROSENSTEIN-RODAN, P. N. Problems of Industrialisation of Eastern and SouthEastern Europe. The Economic Journal, v. 53, n. 210/211, p. 202-211, 1943.

SABOURIN, E.; CARON, P. Camponeses e fundos de pasto no Nordeste da Bahia. In: GODOI, E. P. DE; MENEZES, M. A. DE; ACEVEDO MARIN, R. E. (Eds.). . Diversidade do campesinato: expressões e categorias. Coleção História social do campesinato no Brasil. 1a ed ed. São Paulo, SP: Brasília, DF: Editora UNESP; Núcleo de Estudos Agrários e Desenvolvimento Rural, 2009. p. 89-116.

SANTANA, C. A. M. et al. Política Agrícola- Avanços e retrocessos ao longo de uma trajetória positiva. In: BUAINAIN, A. M. et al. (Eds.). . O mundo rural no Brasil do século 21: a formação de um novo padrão agrário e agrícola. 1a edição ed. Brasília, DF: Embrapa, 2014. p. 797-825.

SIMAS, M.; PACCA, S. Energia eólica, geração de empregos e desenvolvimento sustentável. Estudos Avançados, v. 27, n. 77, p. 99-116, 2013.

STIRLING, A. Developing 'Nexus Capabilities': towards transdisciplinary methodologies. Sussex: The Nexus Network, jun. 2015.

SWATUK, L. A.; CASH, C. Perspectives on the Nexus: Water, Energy and Food Security in an Era of Climate Change. In: SWATUK, L. A.; CASH, C. (Eds.). . Water, Energy, Food and People Across the Global South. Cham: Springer International Publishing, 2018. p. 1-13.

TURNER, B. L. et al. A framework for vulnerability analysis in sustainability science. Proceedings of the National Academy of Sciences, v. 100, n. 14, p. 8074-8079, 7 ago. 2003. 